\title{
Assessing the Impact of Clinically Themed Dissection-based Projects on Anatomy Knowledge in the Veterinary Pre-clinical Curriculum
}

\author{
Margot C Labberte, Colm Reid, David Kilroy, Arun HS Kumar*
}

\begin{abstract}
Cadaveric dissection-based anatomy teaching is being reduced or removed in several veterinary schools driven by infrastructural, economic and ethical issues. This may be due to a view that the learning of anatomy is purely a knowledge-based process. Using clinical themed dissection-based projects in the first year of the veterinary curriculum we show that cadaveric dissection is not only important in gaining clinically relevant anatomy knowledge but has other benefits including improvement of dissection skills, technical communication and group working skills. We believe that adopting such innovative approaches to anatomy dissection classes are critical for vertical integration across the veterinary curriculum and support during the transition from preclinical to clinical years.
\end{abstract}

Key words: Cadaveric dissection, Anatomy, Technical skills, Vertical integration, Veterinary anatomy, Education, Teaching.

\section{INTRODUCTION}

With the removal/restriction of a dissection-based approach to teaching structural biology at the secondary school level, students entering the veterinary medicine programme may find it challenging to grasp anatomical knowledge from day one of their curriculum. ${ }^{1-3}$ Knowledge of anatomy is essential for understanding the relevance and application of the other pre/para clinical and clinical subjects taught in the veterinary curriculum. ${ }^{1,2,-8}$ The knowledge of anatomy is classically gained by performing cadaveric dissections in the early years of the veterinary curriculum..$^{6,9-13}$ However in recent years due to ethical, financial, time and infrastructure issues, the value of cadaveric dissections in anatomy teaching is increasingly questioned. ${ }^{10-12,14-17}$ Despite the evidence that a cadaveric dissection-based approach offers superior understanding of clinically-relevant anatomy and surgical techniques, the depth and duration of teaching anatomical content is in decline., $2,4,14,18,19$ This trend is of immense concern as it is likely to increase the gap between anatomical dissection skills required during the initial years of veterinary curriculum and the surgical skills required in an operating room in the clinical years. ${ }^{1,2,4}$ Such gaps between the preclinical and clinical years may be unnecessary barriers in facilitating vertical integration in the veterinary curriculum. Furthermore, the impact of this concern is evident in students in our school and in other schools of Veterinary Medicine who frequently in their clinical years choose to volunteer

Cite this article : Labberte M, Reid C, Kilroy D, Kumar AHS. Assessing the Impact of Clinically Themed Dissectionbased Projects on Anatomy Knowledge in the Veterinary Pre-clinical Curriculum. BEMS Reports. 2019;5(1):1-4. as demonstrators in dissection classes to refresh anatomy knowledge relevant for clinical skills.

Dissection classes are not merely aimed at training the student on the knowledge of anatomy; these classes also help develop key competencies, ethical perspectives, technical communication skills, curiosity, evidence-based understanding, functional thinking and teamwork, all of which are collectively an essential part of veterinary professional education. . $^{3,715-17,20-23}$ While a considerable number of studies have evaluated the merits of a dissection-based approach to understanding anatomy in human medicine, evidence from the veterinary curriculum is very limited. . $2,4,7^{-}$ Hence the present study was designed to capture an objective perception of student views on the merits of cadaveric dissections in the first semester of their Veterinary Medicine programme.

\section{MATERIALS AND METHODS}

A five-item questionnaire with a five-point response scale was designed (Table 1) to capture feedback from first year students enrolled to the "Introduction to practical application of Veterinary Anatomy" module of the 5-year MVB programme at The School of Veterinary Medicine, University College Dublin, Ireland. Students enrolled to this module were tasked to perform a dissection-based group project on a relevant clinical case with adequate guidance from subject experts. Following completion of the dissection project, the students presented their work as a

\section{Margot Labberte, Colm Reid, David Kilroy, Arun HS Kumar*}

School of Veterinary Medicine, University College Dublin, National University of Ireland-Dublin, Belfield, Dublin, IRELAND.

\section{Correspondence}

Dr. Arun HS Kumar, DVM, PhD.

School of Veterinary Medicine University College Dublin, Belfield, Rm 216, Dublin-04, IRELAND.

Ph.no: +353 17166230

Email: arun.kumar@ucd.ie

History

- Submission Date: 04-03-2019;

- Review completed: 24-04-2019.

- Accepted Date: 02-05-2019.

DOI : 10.5530/bems.5.1.1

Article Available online http://www.bemsreports.org

Copyright

(C) 2019 Phcog.Net. This is an openaccess article distributed under the terms of the Creative Commons Attribution 4.0 International license. 


\section{Table 1: Template of feedback questionnaire.}

1 The objectives and expectations from the project were clearly explained to our group.

2 The support and guidance provided to us was adequate for us to engage with the project requirements.

3 The functional and clinical anatomy projects have helped us gain better insights to learning anatomy.

4 The functional and clinical anatomy projects have helped us improve our technical skills required for anatomy dissection class.

5 The functional and clinical anatomy projects have helped us effectively work in teams and improve our technical communication skills.

poster to an open audience and independent subject experts as well as peer self-evaluation was employed to grade their work. Subsequent to this, students were asked to anonymously complete the feedback questionnaire online. The student responses to the questionnaire were collated over three years (from 2016 to 2018) and analysed statistically using Graph Pad Prism version V software.

\section{RESULTS}

Of the 261 students who were given the questionnaire over a three-year period, 222 students responded with their feedback, giving a response rate of $88.8 \pm 7.8 \%$. The yearly response rate varied from 80.46 to $95.89 \%$. Over $80 \%$ of the students agreed that the objectives of the project were clearly explained to them (Figure 1) while $8.7 \pm 1.6 \%$ and $8.0 \pm 2.3 \%$ of the students were either neutral or expressed satisfaction respectively with the way the objectives of the project were explained to them. About $1.47 \pm 1.47 \%$ of students were unsatisfied with the description of project objectives (Figure 1).

Over $85 \%$ of the students indicated that they received adequate support and guidance for working on their project, while $5.8 \pm 1.4 \%$ and $6.5 \pm 0.6 \%$ of the students were either neutral or satisfied with the support and guidance given to them (Figure 2).

\section{Objectives Clearly expain،}

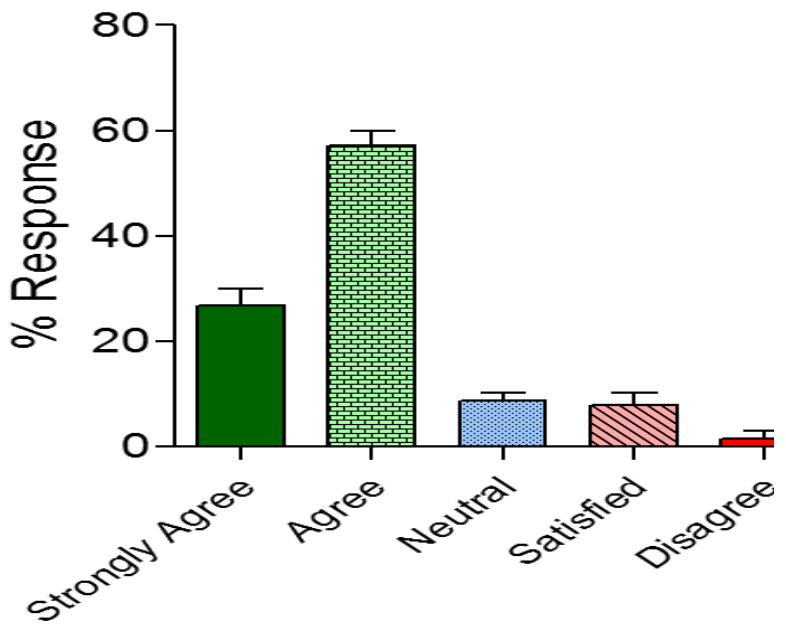

Figure 1: Student response to question on whether the objectives and expectations from the project were clearly explained to their group. Data is presented as Mean \pm SD $(n=222)$.
When asked about the impact of the dissection-based project on the student's anatomy knowledge, over $95 \%$ of the students indicated the benefits of the dissection project on their understanding of anatomical structures (Figure 3). Less than $4 \%$ of the students were neutral on the benefits of the dissection project, while none of the students disagreed with the benefits of the dissection project in gaining anatomy knowledge (Figure 3).

A large majority (> 85\%) of the students agreed that the dissection projects significantly improved their dissection skills (Figure 4). However, $9.43 \pm 0.85 \%$ of the students indicated that the dissection projects had no influence on their dissection skills (Figure 4 ), while $3.6 \pm 0.8 \%$ of students were satisfied with their dissection skills following the project (Figure 4). A negligible fraction $(0.7 \pm 0.7 \%)$ of the students disagreed with the use of the dissection project in improving their dissection skills (Figure 4).

Dissection projects had a significant impact on improving student's technical communication skills. Over $90 \%$ of the students agreed that the process of engagement during the dissection projects improved their technical communication skills (Figure 5). Only less than $4.4 \%$ of the students were either neutral or just satisfied with the changes in their technical communication skills (Figure 5). None of the students disagreed with the influence of dissection projects on improving their technical communication skills (Figure 5).

\section{DISCUSSION}

Along with anatomy textbooks, cadaveric dissection has been the classical approach to gaining anatomy knowledge in the veterinary medicine curriculum. This activity, which occupied significant aspects of the preclinical years of the veterinary medicine curriculum, has been progressively reduced due to several factors including the perception that large volumes of detailed anatomical information are unnecessary in the veterinary programme. While the merits of this are debatable,,$^{1,2,4,7,8,17,23}$ the collateral damage of such a perception has resulted in a significant reduction in the veterinary anatomy syllabus across veterinary schools and a more general debate about the value of a classical approach to teaching anatomy. ${ }^{1,2,4}$ Here we have shown that a dissection-based approach to teaching anatomy under expert supervision not only enhances relevant anatomical knowledge but is also valuable in improving dissection and technical communication skills, skills which are benificial throughout

\section{Adequate Support and Guidance}

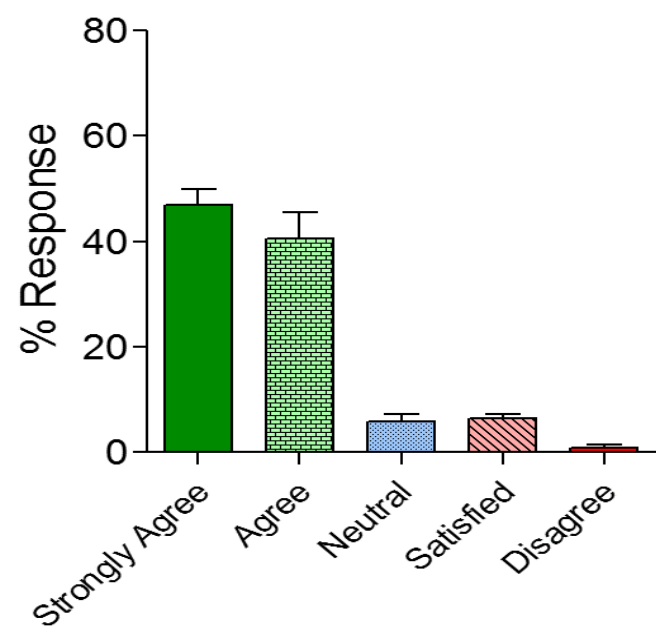

Figure 2: Student response to question on whether the support and guidance provided to them was adequate to engage with the project requirements. Data is presented as Mean $\pm S D(n=222)$. 


\section{Improved Anatomy Knowledge}

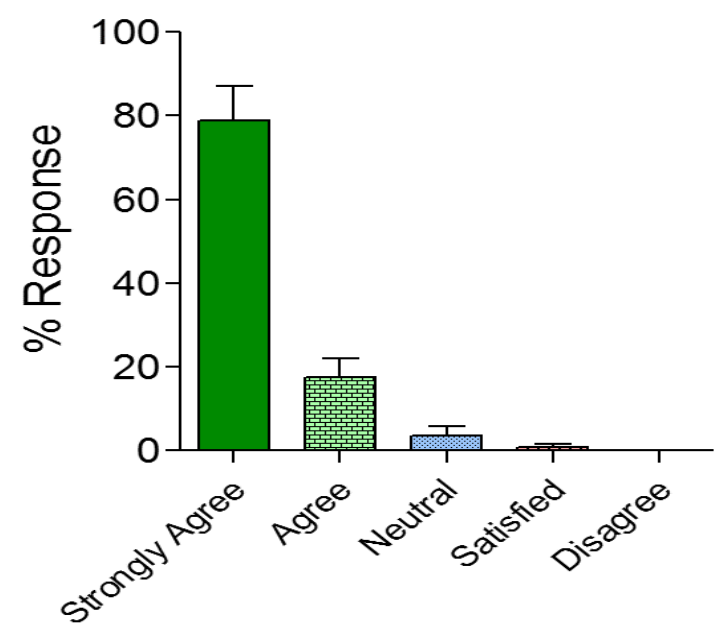

Figure 3: Student response to question on whether the functional and clinical anatomy projects have helped them gain better insights to learning anatomy. Data is presented as Mean \pm SD $(n=222)$.

\section{Improved Dissection Skills}

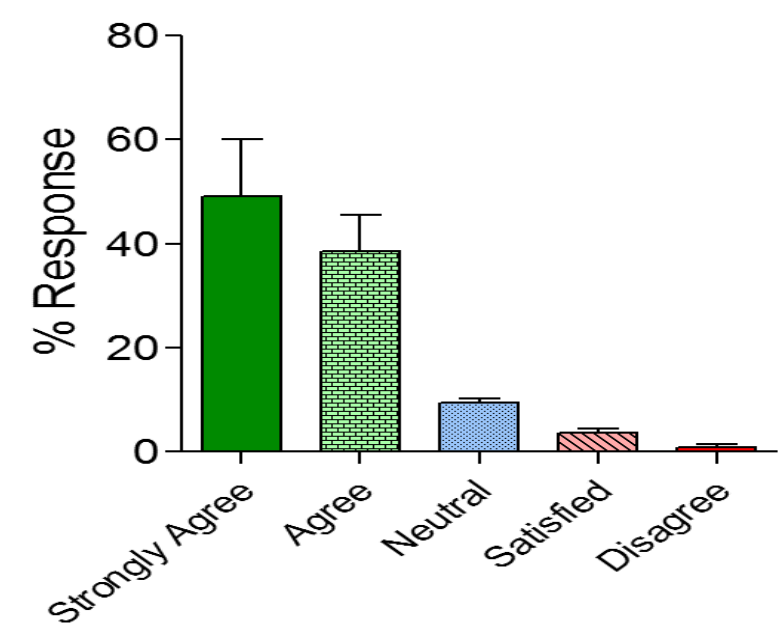

Figure 4: Student response to question on whether the functional and clinical anatomy projects have helped them improve their technical skills required for anatomy dissection class. Data is presented as Mean \pm SD $(n=222)$.

the veterinary curriculum. Clearly explaining the benefits to the students of cadaveric dissections together with providing adequate expert support and guidance is valuable for enhancing student engagement and achieving optimal benefits for the students from the cadaveric dissection-based anatomy learning process.

The quality of the structuring and supervision offered is perhaps the reason for less than $2 \%$ of students expressing disagreement with the benefits of cadaveric dissections in learning anatomy. This fraction of students can be considered as negligible on account of a consistent very high response rate $(88.8 \pm 7.8 \%)$ over the three years in our study.

Another reason for the students gaining higher benefits from the cadaveric dissections is perhaps the clinical case themes set for each group. Streamlining the dissection process to a clinical scenario helps the students to associate the importance of the anatomy to potential clinical

\section{Improved Technical Communicat}

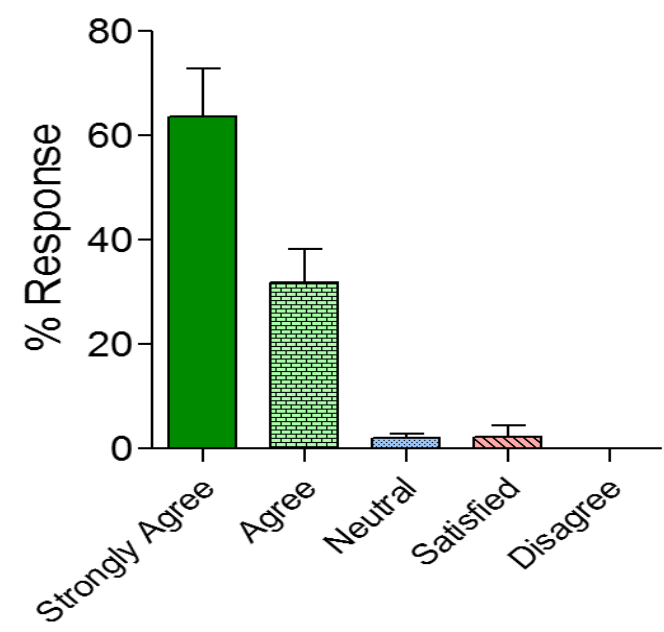

Figure 5: Student response to question on whether the functional and clinical anatomy projects have helped them effectively work in teams and improve their technical communication skills. Data is presented as Mean \pm SD $(n=222)$.

situations they may encounter in future and this triggers a needs based process for learning, thereby achieving better student engagement and learning. ${ }^{1,2,4,5,10,11,24,25}$

Although anatomy is a knowledge-based subject, integrating clinical theme based cadaveric dissections can facilitate complementary development of dissection skills and technical communication in early stage veterinary students. Such an approach is also valuable in effectively achieving vertical integration across the veterinary curriculum. Hence we recommend positive reinforcement of the anatomy syllabus in Veterinary Schools to support these aims.

\section{ACKNOWLEDGEMENT}

None

\section{CONFLICT OF INTEREST}

The authors declare no conflict of interest.

\section{REFERENCES}

1. Kucukaslan O, Erdogan S, Bulut I. Turkish Undergraduate Veterinary Students Attitudes to Use of Animals and Other Teaching Alternatives for Learning Anatomy. J Vet Med Educ. 2018;1-12.

2. Gummery E, Cobb KA, Mossop LH, Cobb MA. Student Perceptions of Veterinary Anatomy Practical Classes: A Longitudinal Study. J Vet Med Educ. 2018;45(2):163-76

3. Patel SB, Mauro D, Fenn J, Sharkey DR, Jones C. Is dissection the only way to learn anatomy? Thoughts from students at a non-dissecting based medical school. Perspect Med Educ. 2015;4(5):259-60.

4. McNulty MA, Lazarus MD. An Anatomy Pre-Course Predicts Student Performance in a Professional Veterinary Anatomy Curriculum. J Vet Med Educ. 2018;45(3):330-42.

5. Little WB, Artemiou E, Conan A, Sparks C. Computer Assisted Learning Assessment of the Veterinary Virtual Anatomy Education Software IVALA. Vet Sci. 2018;5(2):58.

6. Laakkonen J, Muukkonen H. Fostering Students' Collaborative Learning Competencies and Professional Conduct in the Context of Two Gross Anatomy Courses in Veterinary Medicine. Anat Sci Educ. 2018;12(2):154-63.

7. Salomaki T, Laakkonen J, Ruohoniemi M. Students as teachers in an anatomy dissection course. J Vet Med Educ. 2014;41(1):60-7.

8. Provo JA, Lamar $\mathrm{CH}$. Prosection as an approach to student-centered learning in veterinary gross anatomy. J Am Vet Med Assoc. 1995;206(2):158-61.

9. Williams SR, Thompson KL, Notebaert AJ, Sinning AR. Prosection or Dissection: 
Which is Best for Teaching the Anatomy of the Hand and Foot?. Anat Sci Educ. 2018;12(2):173-80

10. Juo YY, et al. Mixed-Method Evaluation of a Cadaver Dissection Course for General Surgery Interns: An Innovative Approach for Filling the Gap Between Gross Anatomy and the Operating Room. J Surg Educ. 2018;75(6):1526-34.

11. Paech D, et al. Cadaver-specific CT scans visualized at the dissection table combined with virtual dissection tables improve learning performance in general gross anatomy. Eur Radiol. 2017;27(5):2153-60.

12. Kumar N, Rahman E. Effectiveness of teaching facial anatomy through cadaver dissection on aesthetic physicians' knowledge. Adv Med Educ Pract. 2017;8:475-80.

13. Cake MA. Deep dissection: motivating students beyond rote learning in veterinary anatomy. J Vet Med Educ. 2006;33(2):266-71.

14. Kinirons SA, Reddin VM, Maguffin J. Effects of Alternating Dissection with Peer Teaching and Faculty Prosected Cadaver Demonstrations in a Physical Therapy and Occupational Therapy Gross Anatomy Course. Anat Sci Educ. 2018.

15. Abdel MEM, Khalil MK. Measuring medical students' motivation to learning anatomy by cadaveric dissection. Anat Sci Educ. 2017;10(4):363-71.

16. Ajani RS, Oladapo O. Attitudes and perception of medical and dental preclinical undergraduates in a Nigerian medical school towards cadaveric dissection. Afr J Med Med Sci. 2011;40(2):139-46.

17. Theoret $\mathrm{CL}$, Carmel EN, Bernier S. Why dissection videos should not replace cadaver prosections in the gross veterinary anatomy curriculum: results from a comparative study. J Vet Med Educ. 2007;34(2):151-6.

18. Thompson AR, Marshall AM. Participation in Dissection Affects Student Performance on Gross Anatomy Practical and Written Examinations: Results of a Four-Year Comparative Study. Anat Sci Educ. 2019.

19. Bietzk E, Weller R, Simons V, Channon SB. Anatomy Teaching, a "Model" Answer? Evaluating "Geoff", a Painted Anatomical Horse, as a Tool for Enhancing Topographical Anatomy Learning. Anat Sci Educ. 2018.

20. Locketz GD, et al. Anatomy-Specific Virtual Reality Simulation in Temporal Bone Dissection: Perceived Utility and Impact on Surgeon Confidence. Otolaryngol Head Neck Surg. 2017;156(6):1142-9.

21. Rehkamper G. Human Dissection in Medical Education: More than Just Anatomy. GMS J Med Educ. 2016;33(5):Doc68.

22. Bergman EM. Discussing dissection in anatomy education. Perspect Med Educ. 2015;4(5):211-3.

23. Ginneken VCJ, Vanthourout G. Rethinking the learning and evaluation environment of a veterinary course in gross anatomy: the implementation of an assessment and development center and an E-learning platform. J Vet Med Educ. 2005;32(4):537-43.

24. Darras KE, Forster BB, Nicolaou S, Munk PL. A Golden Opportunity for Radiologists: Bringing Clinical Relevance to Undergraduate Anatomy Through Virtual Dissection. Can Assoc Radiol J. 2017;68(3):232-3.

25. Resti J, Li P, Orebaugh SL. Computer dissection program to enhance understanding of ultrasound anatomy. Med Educ. 2016;50(11):1165-66.

Cite this article : Labberte MC, Reid C, Kilroy D, Kumar AHS. Assessing the Impact of Clinically Themed Dissection-based Projects on Anatomy Knowledge in the Veterinary Pre-clinical Curriculum. BEMS Reports. 2019;5(1):1-4. 